\title{
Selenium absorption and retention from a selenite- or selenate-fortified milk-based formula in men measured by a stable-isotope technique
}

\author{
Peter Van Dael*, Lena Davidsson $\dagger$, Rafael Muñoz-Box, Laurent B. Fay and Denis Barclay \\ Nestlé Research Centre, PO Box 44, Vers-chez-les-Blanc, CH-1000 Lausanne, Switzerland \\ (Received 11 January 2000 - Revised 10 July 2000 - Accepted 04 August 2000)
}

\begin{abstract}
The present study was designed to determine the apparent absorption and retention of the inorganic Se compounds $\mathrm{SeO}_{3}{ }^{2-}$ and $\mathrm{SeO}_{4}{ }^{2-}$, which are commonly used for Se fortification of clinical nutrition products and infant formulas. Ten healthy men were fed a milk-based formula labelled with $40 \mu \mathrm{g} \mathrm{Se}$ as ${ }^{74} \mathrm{SeO}_{3}{ }^{2-}$ or ${ }^{76} \mathrm{SeO}_{4}{ }^{2-}$ on two consecutive days using a randomised crossover design. Se stable-isotope analysis of $9 \mathrm{~d}$ complete collections of urine and faeces was used to calculate apparent Se absorption and retention. Se retention from ${ }^{74} \mathrm{SeO}_{3}{ }^{2-}(41.0$ (SD $8.4) \%)$ and from ${ }^{76} \mathrm{SeO}_{4}{ }^{2-}(46.0(\mathrm{SD} 7.9) \%)$ was not significantly different $(P>0.05)$. However, Se absorption was significantly higher from $\mathrm{SeO}_{4}{ }^{2-}$ than from $\mathrm{SeO}_{3}{ }^{2-}$ (91.3 (SD 1.4) $\%$ v. 50.2 (SD 7.8) \%, $P<0.05$ ). Urinary excretion of the administered dose was $9.2($ SD 1.8$) \%$ for ${ }^{74} \mathrm{SeO}_{3}{ }^{2-}$ and 45.3 (SD 8.2) $\%$ for ${ }^{76} \mathrm{SeO}_{4}{ }^{2-}(P<0.05)$. Urinary Se excretion kinetics differed significantly for the two Se compounds; $90 \%$ of the total urinary Se was excreted after $121 \mathrm{~h}$ for ${ }^{74} \mathrm{SeO}_{3}{ }^{2-}$ and after $40 \mathrm{~h}$ for ${ }^{76} \mathrm{SeO}_{4}{ }^{2-}(P<0 \cdot 05)$. These results suggest that although $\mathrm{Se}$ absorption and urinary excretion differ for $\mathrm{SeO}_{3}{ }^{2-}$ and $\mathrm{SeO}_{4}{ }^{2-}$, both Se compounds are equally well retained when administered at a relatively low dose $(40 \mu \mathrm{g} \mathrm{Se})$. The nutritional impact of Se fortification of foods would thus be expected to be similar when $\mathrm{SeO}_{4}{ }^{2-}$ or $\mathrm{SeO}_{3}{ }^{2-}$ are used.
\end{abstract}

\section{Selenium fortification: Selenium absorption: Selenium retention: Inorganic selenium} compounds: Stable isotopes

Se is an essential trace element for human subjects (National Research Council, 1989). Se is an integral part of glutathione peroxidase (GSH-Px), an enzyme involved in cellular protection against oxidative damage, and of iodothyronine deiodinase which catalyses the conversion of thyroxine into triiodothyronine (Zachara, 1993). Several other selenoproteins, such as selenoprotein $\mathrm{P}$, have been isolated, but their physiological role is still not fully elucidated (Zachara, 1993). In addition, Se has been reported to play a role in the maintenance of optimal immune response (Chandra, 1997), and the role of Se in the emergence of viral mutations has been documented (Beck, 1996). Recently, the impact of Se supplementation on the incidence of certain cancers (Clark et al. 1996) was reported.

Low dietary Se intake has been associated with a number of deficiency symptoms, of which Keshan disease, a fatal cardiomyopathy endemic to low-Se areas in China, is the most extensively documented (Lockitch, 1989). Populations at risk of impaired Se status are patients on long-term parenteral or enteral nutrition without Se supplementation (Levander, 1984) and infants consuming infant formulas with a low Se content (Litov \& Combs, 1991). Although no overt clinical symptoms of Se deficiency have been diagnosed in these individuals, cases of cardiac and muscular dystrophies have been reported in patients on long-term total parenteral nutrition (Casey \& Hambidge, 1985; Hambidge, 1985; Vinton et al. 1987; Kelly et al. 1988)

Food fortification with Se is not widely used, except for clinical products such as enteral and parenteral nutrition products and infant formulas. Inorganic Se compounds, $\mathrm{SeO}_{3}{ }^{2-}$ or $\mathrm{SeO}_{4}{ }^{2-}$, are typically used for food fortification and information about bioavailability, absorption and retention of these Se compounds in human subjects is needed to estimate the nutritional impact of Se fortification.

\footnotetext{
Abbreviations: GSH-Px, glutathione peroxidase; Hb, haemoglobin; HGAAS, hydride-generation atomic absorption spectrometry.

* Corresponding author: Dr Peter Van Dael, fax +4121785 8563, email peter.van-dael@rdls.nestle.com

$\dagger$ Present address: Laboratory for Human Nutrition, Institute of Food Science, Swiss Federal Institute of Technology, PO Box 474, CH-8803 Rüschlikon, Switzerland.
} 
Previous studies of Se bioavailability have focused mainly on the comparison between inorganic Se, in particular $\mathrm{SeO}_{3}{ }^{2-}$, and organic Se compounds, selenomethionine or Se-rich yeast (Alfthan et al. 1991; Xia et al. 1992; Nève, 1995). Only very limited data on Se bioavailability from inorganic compounds $\left(\mathrm{SeO}_{3}{ }^{2-}\right.$ and $\left.\mathrm{SeO}_{4}{ }^{2-}\right)$ are available. Furthermore, until now, no information about Se absorption and retention from $\mathrm{SeO}_{3}{ }^{2-}$ and $\mathrm{SeO}_{4}{ }^{2-}$ after intake of relatively small amounts of the Se compounds, relevant to food fortification, has been reported. The recent development of stable-isotope techniques offers the possibility of monitoring absorption and retention of trace elements without introducing radiation exposure (Sandström et al. 1993).

The aim of the present study was to compare apparent $\mathrm{Se}$ absorption and retention from $\mathrm{SeO}_{3}{ }^{2-}$ and $\mathrm{SeO}_{4}{ }^{2-}$ in men using a stable-isotope technique. The inorganic Se compounds were added to a milk-based formula in quantities relevant to food fortification. A milk-based formula was selected as the food vehicle since it represents the most common products fortified with Se (i.e. products used for enteral nutrition or infant formulas).

\section{Materials and methods}

\section{Subjects}

Ten healthy men, 24-36 (mean 30) years old, were recruited from personnel at the Nestlé Research Centre, Lausanne, Switzerland. The aims and procedures of the study were explained verbally and in writing before enrolment in the study. All subjects gave written informed consent. A medical examination was carried out before enrolment. Medication, dietary supplements and high-Se food items (i.e. offal meat, fish and other seafoods) were excluded during the study. In all other respects subjects maintained their normal lifestyle and dietary habits during the study. None of the subjects consumed dietary supplements containing Se.

The study protocol was reviewed and approved by the external ethical committee of the Nestlé Research Centre and followed the guidelines of the Helsinki Declaration regarding human subjects.

\section{Stable isotope labels}

Highly-enriched elemental ${ }^{74} \mathrm{Se}\left({ }^{74} \mathrm{Se} 98.2 \%,{ }^{76} \mathrm{Se} 1.8 \%\right.$, other Se isotopes $<0.1 \%),{ }^{76} \mathrm{Se}\left({ }^{74} \mathrm{Se} 1.2 \%,{ }^{76} \mathrm{Se} 98.5 \%\right.$, ${ }^{77} \mathrm{Se} 0.2 \%$, other Se isotopes $\left.<0.03 \%\right)$ and ${ }^{82} \mathrm{Se}\left({ }^{74} \mathrm{Se}\right.$ $0.06 \%,{ }^{76} \mathrm{Se} 0.62 \%,{ }^{77} \mathrm{Se} 0.56 \%,{ }^{78} \mathrm{Se} 1.76 \%,{ }^{80} \mathrm{Se}$ $4.8 \%,{ }^{82} \mathrm{Se} 92.2 \%$ ) were purchased from Isotec (St. Quentin, France). Elemental $\mathrm{Se}$ was converted into ${ }^{74} \mathrm{SeO}_{3}{ }^{2-},{ }^{76} \mathrm{SeO}_{4}{ }^{2-}$ and ${ }^{82} \mathrm{SeO}_{3}{ }^{2-} \cdot \mathrm{SeO}_{3}{ }^{2-}$ was prepared by dissolving a precise amount of elemental Se (approximately 2.5-10 mg; weighed on a high-precision analytical balance) into $1 \mathrm{ml}$ concentrated $\mathrm{HNO}_{3}$. The solution was heated for $1 \mathrm{~h}$ at $60^{\circ} \mathrm{C}$ under $\mathrm{N}_{2}$. The clear solution (approximately $0.2 \mathrm{ml}$ ) was made up to $20 \mathrm{ml}$ with deionised water, filtred through a $0.22 \mu \mathrm{m}$ Teflon filter and stored at $4{ }^{\circ} \mathrm{C}$. $\mathrm{SeO}_{4}{ }^{2-}$ labels were prepared from the $\mathrm{SeO}_{3}{ }^{2-}$ solution after evaporation to dryness at $100^{\circ} \mathrm{C}$ under $\mathrm{N}_{2} . \mathrm{H}_{2} \mathrm{O}_{2}(5 \mathrm{ml})$ was added to the white precipitate to oxidise $\mathrm{SeO}_{3}{ }^{2-}$. The solution was gently heated to $70^{\circ} \mathrm{C}$ and $0.2 \mathrm{ml} \mathrm{KOH}(2 \mathrm{~mol} / \mathrm{l})$ was added. The volume was reduced under $\mathrm{N}_{2}$ to about $1 \mathrm{ml}$ at $70^{\circ} \mathrm{C}$ and the oxidation step repeated three times. The solution was evaporated to dryness, the white precipitate redissolved in deionised water and $0.1 \mathrm{ml}$ concentrated $\mathrm{HNO}_{3}$ was added. Finally, the solution was made up to $20 \mathrm{ml}$, filtered through a $0.22 \mu \mathrm{m}$ Teflon filter and stored at $4^{\circ} \mathrm{C}$.

Speciation of $\mathrm{SeO}_{3}{ }^{2-}$ and $\mathrm{SeO}_{4}{ }^{2-}$ stable-isotope solutions was performed by continuous-flow hydride-generation atomic absorption spectrometry (HGAAS) based on the principle that only $\mathrm{SeO}_{3}{ }^{2-}$, but not $\mathrm{SeO}_{4}{ }^{2-}$, can be directly measured by HGAAS on reaction with a $\mathrm{NaBH}_{4}$ reductant solution (Van Dael et al. 1995). Determination of $\mathrm{SeO}_{4}{ }^{2-}$ by HGAAS requires an $\mathrm{HCl}$ reduction step before HGAAS analysis.

Se concentration of the stable-isotope solutions was verified by continuous-flow HGAAS (Van Dael et al. 1995). For each isotope, stock solutions of $100 \mu \mathrm{g} \mathrm{Se} / \mathrm{ml}$ in $\mathrm{HNO}_{3}(0.01 \mathrm{~mol} / \mathrm{l})$ were prepared.

\section{Test meals}

A commercial ready-to-feed milk-based formula was used as the test meal (Carnation Follow-Up ${ }^{\circledR}$; Carnation, Glendale, CA, USA). The product contained (g/l): protein $32 \cdot 5$, fat $26 \cdot 6$, carbohydrate 85.6 . Each test meal was prepared by the addition of $40 \mu \mathrm{g} \mathrm{Se}$ as ${ }^{74} \mathrm{SeO}_{3}{ }^{2-}$ or ${ }^{76} \mathrm{SeO}_{4}{ }^{2-}$ to $500 \mathrm{~g}$ formula. Test meals were prepared $15 \mathrm{~h}$ before administration and stored at $4^{\circ} \mathrm{C}$ until consumed.

\section{Study design}

A randomised crossover design was employed. Labelled test meals $\left({ }^{74} \mathrm{SeO}_{3}{ }^{2-}\right.$ - or ${ }^{76} \mathrm{SeO}_{4}{ }^{2-}$-fortified formula) were administered after an overnight fast on two consecutive days. No food or drink was allowed for $3 \mathrm{~h}$ following intake of the labelled test meals. Complete collection of faeces and urine were made for $10 \mathrm{~d}$, starting immediately after intake of the first test meal. Individual portions of faeces were collected in acid-washed plastic containers. Urine was collected in acid-washed plastic bottles in $4 \mathrm{~h}$ portions during the first $4 \mathrm{~d}$ followed by $24 \mathrm{~h}$ collections for the remaining period of the study. A baseline $24 \mathrm{~h}$ urine sample was collected the day preceding the study. All excreta were labelled with the subject's code, date and hour of collection and immediately frozen at $-40^{\circ} \mathrm{C}$. Faecal material was freeze-dried and homogenised using acidwashed mortars and pestles. A faecal marker, $100 \mathrm{mg}$ Brilliant blue, was used to determine the start of the faecal monitoring. A gelatine capsule containing the dye was ingested on the evening before intake of the first test meal.

All individual faecal and urine samples $(4 \mathrm{~h}$ and $24 \mathrm{~h}$ collections) were analysed for total Se content and $\mathrm{Se}$ isotopic ratios.

A venous blood sample $(20 \mathrm{ml})$ was drawn after an overnight fast into heparinised tubes for assessment of Se status. Plasma and erythrocytes were separated by centrifugation $\left(2000 \mathrm{~g}\right.$ at $4^{\circ} \mathrm{C}$ for $\left.15 \mathrm{~min}\right)$. Erythrocytes were 
washed twice with saline $(0.9 \mathrm{~g} \mathrm{NaCl} / \mathrm{l})$. Plasma and erythrocyte samples were stored at $-80^{\circ} \mathrm{C}$ until analysed.

\section{Analytical methods}

Total Se and stable-isotope ratios in samples of faeces and urine were determined after acid digestion and derivatisation by GC-MS (Van Dael et al. 1998). Briefly, samples of urine and faeces were acid-digested using a mixture of $\mathrm{HNO}_{3}-\mathrm{HClO}_{4}(3: 1, \mathrm{v} / \mathrm{v})$ followed by the addition of $\mathrm{HCl}$ to convert all $\mathrm{Se}$ to $\mathrm{SeO}_{3}{ }^{2-}$, which was then derivatised with 4-nitro-phenylene-diamine to form the volatile piazselenole before the analysis by GC-MS. Total Se in the faecal and urine samples was determined by isotope-dilution GC-MS using ${ }^{82} \mathrm{SeO}_{3}{ }^{2-}$ as a spike. The Se analysis was validated against the standard reference material NIST 2670 toxic metals in freeze-dried urine (National Institute of Standards and Technology, Gaithersburg, MD, USA).

Total Se in the milk-based formula was determined by continuous-flow HGAAS (Van Dael et al. 1995) and validated against standard reference material NIST 1549 non-fat milk powder (National Institute of Standards and Technology).

Plasma and erythrocyte Se levels were determined by continuous-flow HGAAS (Van Dael et al. 1995) and expressed as $\mu \mathrm{g} \mathrm{Se} / \mathrm{l}$ and $\mu \mathrm{g} \mathrm{Se} / \mathrm{g}$ haemoglobin $(\mathrm{Hb})$ respectively. The analysis was validated against a commercial whole-blood and serum quality-control material (Seronorm trace elements whole-blood batch no. 030016 and serum batch no. 010017; Nycomed, Oslo, Norway). Hb was analysed by the cyanomethaemoglobin technique (Makarem, 1974).

Plasma and erythrocyte GSH-Px activities were determined according to Belsten \& Wright (1995) and expressed per $\mathrm{mg}$ protein and per $\mathrm{g} \mathrm{Hb}$ respectively. Plasma protein concentrations were determined using a colorimetric method (Pierce BCA, Rockford, IL, USA).

\section{Apparent selenium absorption and retention}

Apparent Se absorption and retention were calculated according to Turnlund et al. (1993). Apparent absorption of ${ }^{74} \mathrm{Se}$ and ${ }^{76} \mathrm{Se}$ was calculated as the difference between the administered dose and the total amount of stable isotopes excreted in faeces. All faecal material collected from the appearance of the faecal marker in the stools until day 9 after administration of the ${ }^{74} \mathrm{Se}$ and ${ }^{76} \mathrm{Se}$ isotope labels was included in the calculation of apparent ${ }^{74} \mathrm{Se}$ and ${ }^{76} \mathrm{Se}$ absorption respectively. Apparent Se retention was based on apparent absorption and adjusted for the amount of ${ }^{74} \mathrm{Se}$ and ${ }^{76} \mathrm{Se}$ excreted in urine collected over $9 \mathrm{~d}$ following the administration of the specific isotope.

In addition, cumulative apparent $\mathrm{Se}$ absorption was calculated based on the faecal excretion during consecutive $24 \mathrm{~h}$ faecal collections (i.e. $24 \mathrm{~h}, 48 \mathrm{~h}, 72 \mathrm{~h}$ etc.) after administration of the labelled test meals. Similarly, cumulative urinary Se excretion was calculated based on consecutive $24 \mathrm{~h}$ urinary collections. Se retention of the stable-isotope doses was calculated as the difference between the cumulative excretion of ${ }^{74} \mathrm{Se}$ and ${ }^{76} \mathrm{Se}$ in faeces and urine.

\section{Statistical evaluation}

Differences in $\mathrm{Se}$ absorption, retention and urinary excretion between $\mathrm{SeO}_{3}{ }^{2-}$ and $\mathrm{SeO}_{4}{ }^{2-}$ were evaluated using the $t$ test procedure for crossover studies according to Hills \& Armitage (1979). Results are expressed as means and standard deviations, and statistical significance is defined as $P<0 \cdot 05$.

\section{Results}

Plasma Se concentration was 81.5 (SD 14.4; range 60.5-

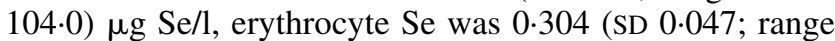
0.248-0.385) $\mu \mathrm{g} \mathrm{Se} / \mathrm{g} \mathrm{Hb}$, plasma GSH-Px was 6.4 (SD 0.8; range 5.3-7.7) units/g protein and erythrocyte GSH-Px activity was 52.4 (SD 6.6; range 41.9-62.8) units/g $\mathrm{Hb}$. Baseline urine Se concentration was 27.8 (SD 7.5; range 15.7-36.4) $\mu \mathrm{g} \mathrm{Se} / \mathrm{l}$ and $24 \mathrm{~h}$ urinary Se excretion was $32 \cdot 1$ (SD 6.1; range 23.8-39.4) $\mu \mathrm{g}$ Se. The Se level of the milkbased formula was 12.6 (SD 0.4) $\mu \mathrm{g} \mathrm{Se} / 1$ (6.0 $\mu \mathrm{g} \mathrm{Se} / 500 \mathrm{~g}$ formula). At least $97.5 \%$ of the elemental stable-isotope labels were transformed into ${ }^{74} \mathrm{SeO}_{3}{ }^{2-},{ }^{76} \mathrm{SeO}_{4}{ }^{2-}$ and ${ }^{82} \mathrm{SeO}_{3}{ }^{2-}$.

Apparent Se retention from ${ }^{74} \mathrm{SeO}_{3}{ }^{2-}$ (41.0 (SD 8.4\%; range $21.9-52.4) \%$ ) and ${ }^{76} \mathrm{SeO}_{4}{ }^{2-}$ (46.0 (SD 7.9; range 33.3-56.1) \%) was not significantly different. However, apparent Se absorption and urinary excretion from the two Se compounds differed considerably. Se absorption was significantly $(P<0 \cdot 05)$ higher from $\mathrm{SeO}_{4}{ }^{2-}(91.3$ (SD 1.4; range $89.5-93.4) \%$ ) than from $\mathrm{SeO}_{3}{ }^{2-}(50 \cdot 2$ (SD 7.8; range $31.9-59 \cdot 2) \%$ ). Urinary excretion of the administered dose represented 9.2 (SD 1.8) $\%{ }^{74} \mathrm{SeO}_{3}{ }^{2-}$ and 45.3 (SD 8.2) $\%$ ${ }^{76} \mathrm{SeO}_{4}{ }^{2-}$, corresponding to 18 and $50 \%$ Se absorbed from $\mathrm{SeO}_{3}{ }^{2-}$ and $\mathrm{SeO}_{4}{ }^{2-}$ respectively.

Cumulative faecal Se excretion (Fig. 1) differed significantly $(P<0.05)$ between the two Se compounds; $90 \%$ of the total faecal Se $\left({ }^{74} \mathrm{Se}\right.$ and $\left.{ }^{76} \mathrm{Se}\right)$ was excreted after 152 (SD 18) $\mathrm{h}$ and 65 (SD 21) h for ${ }^{76} \mathrm{SeO}_{4}{ }^{2-}$ and ${ }^{74} \mathrm{SeO}^{2-}$ respectively. The corresponding times for $95 \%$ excretion were 177 (SD 14) h and 99 (SD 21) h for ${ }^{76} \mathrm{SeO}_{4}{ }^{2-}$ and ${ }^{74} \mathrm{SeO}_{3}{ }^{2-}$ respectively $(P<0 \cdot 05)$. Cumulative urinary Se excretion (Fig. 2) also differed significantly $(P<0.05)$ between the two Se compounds; $90 \%$ of the total urinary Se $\left({ }^{74} \mathrm{Se}\right.$ and ${ }^{76} \mathrm{Se}$ ) was excreted after 40 (SD 30) and 121 (SD 51) h for ${ }^{76} \mathrm{SeO}_{4}{ }^{2-}$ and ${ }^{74} \mathrm{SeO}_{3}{ }^{2-}$ respectively. The corresponding times for $95 \%$ excretion were 84 (SD 52) and 144 (SD 55) h for ${ }^{76} \mathrm{SeO}_{4}{ }^{2-}$ and ${ }^{74} \mathrm{SeO}_{3}{ }^{2-}$ respectively $(P<0.05)$. Under the present experimental conditions, apparent Se retention based on cumulative faecal and urinary excretion of ${ }^{74} \mathrm{Se}$ and ${ }^{76} \mathrm{Se}$ showed that Se retention was not significantly different between $\mathrm{SeO}_{3}{ }^{2-}$ and $\mathrm{SeO}_{4}{ }^{2-}$ $(P>0.05)$ based on $120 \mathrm{~h}\left({ }^{74} \mathrm{SeO}_{3}{ }^{2-} 44.7\right.$ (SD 8.0)\%, ${ }^{76} \mathrm{SeO}_{4}{ }^{2-} 50.0(\mathrm{SD} \mathrm{7.2)} \%)$ or $168 \mathrm{~h}\left({ }^{74} \mathrm{SeO}_{3}{ }^{2-} 42.3\right.$ (SD 8.2) $\%,{ }^{76} \mathrm{SeO}_{4}{ }^{2-} 47 \cdot 6$ (SD 7.6) \%). Apparent Se retention based on 120 or $168 \mathrm{~h}$ cumulative faecal and urinary excretion did not differ significantly from data based on $9 \mathrm{~d}$ collections $(P>0.05)$.

No effect of the order of administration of labelled test meals was detected for Se absorption, urinary excretion or retention. For ${ }^{74} \mathrm{SeO}_{3}{ }^{2-} \mathrm{Se}$ retention was positively correlated with absorption $(r 0.98, P<0.05)$, whereas for 


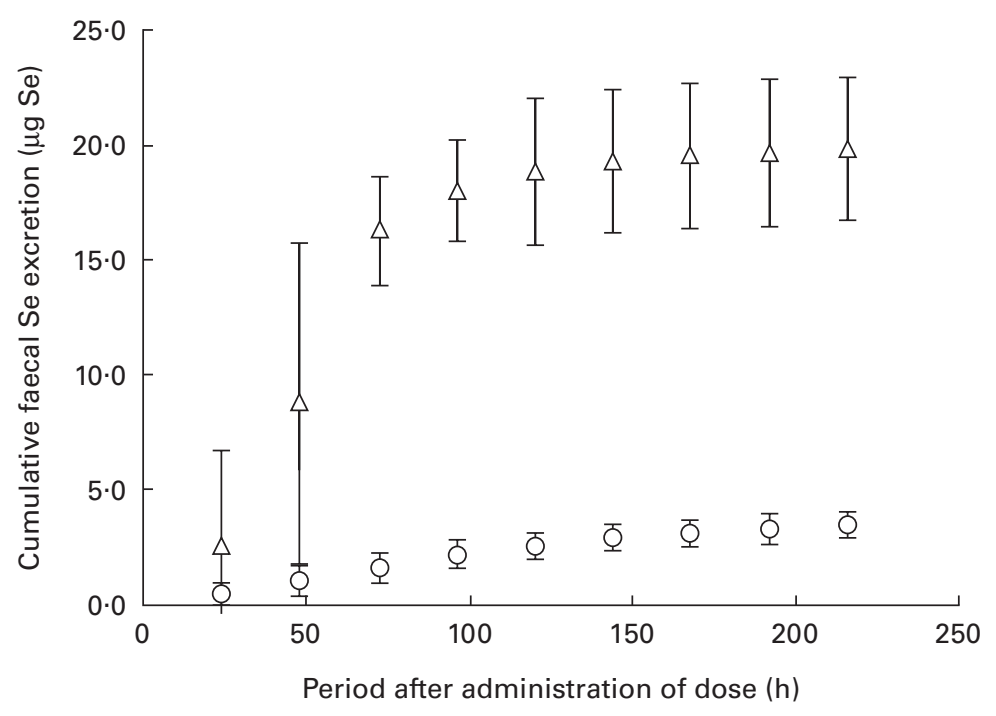

Fig. 1. Cumulative faecal selenium $\left({ }^{74} \mathrm{Se}\right.$ and $\left.{ }^{76} \mathrm{Se}\right)$ excretion by healthy men after a single oral dose of $40 \mu \mathrm{g}$ selenium as ${ }^{74} \mathrm{SeO}_{3}{ }^{2-}(\triangle)$ or ${ }^{76} \mathrm{SeO}_{4}{ }^{2-}(O)$ added to a milk-based formula. Values are means with their standard errors represented by vertical bars for ten subjects. For details of experimental procedures, see p. 159.

${ }^{76} \mathrm{SeO}_{4}{ }^{2-} \mathrm{Se}$ retention and urinary excretion were negatively correlated $(r-0.99, P<0.05)$.

\section{Discussion}

The present study demonstrated that in men, mean apparent Se retention was similar for $\mathrm{SeO}_{3}{ }^{2-}$ and $\mathrm{SeO}_{4}{ }^{2-}$ added to a milk-based infant formula (41\% v. $46 \%$ ), although large differences in absorption and urinary excretion were found. The study design and the dose of $40 \mu \mathrm{g}$ Se for each isotope were based on nutritional considerations. Preliminary analytical data showed that accurate Se stable-isotope measurements in urine and faeces were possible after intake of $40 \mu \mathrm{g}$ Se and demonstrated the analytical feasability of the study (Van Dael et al. 1998). The labelled test meals were administered in a crossover design on two consecutive days. A milk-based formula was selected as the test meal because milk is the most common raw material for dietetic foods such as enteral nutrition products or infant formulas. These milk-based formulas, often the only dietary source of energy and nutrients, are naturally low in Se and often fortified with Se in order to meet dietary Se requirements.

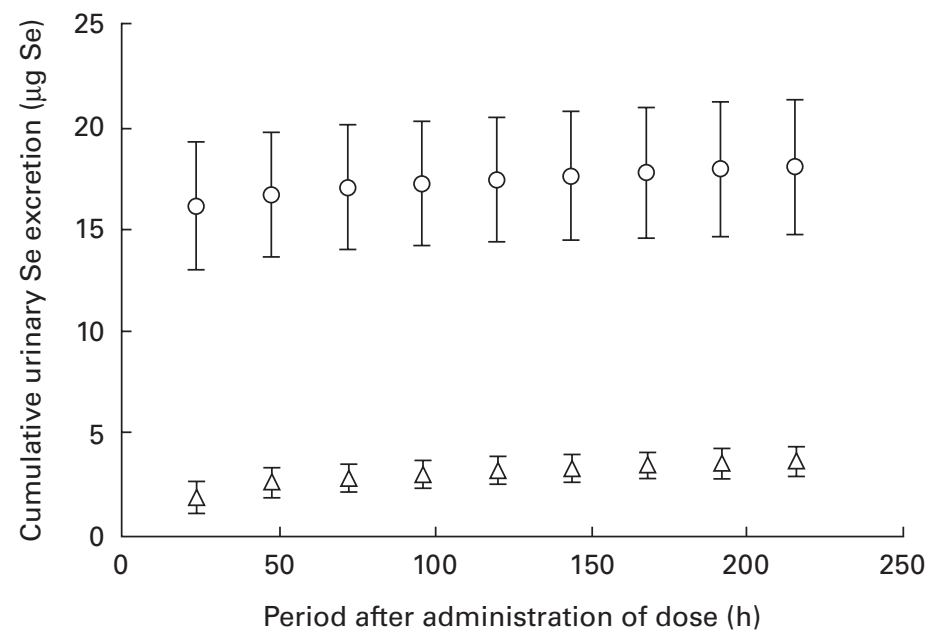

Fig. 2. Cumulative urinary selenium $\left({ }^{74} \mathrm{Se}\right.$ and $\left.{ }^{76} \mathrm{Se}\right)$ excretion by healthy men after a single oral dose of $40 \mu \mathrm{g}$ selenium as ${ }^{74} \mathrm{SeO}_{3}{ }^{2-}(\triangle)$ or ${ }^{76} \mathrm{SeO}_{4}{ }^{2-}(\mathrm{O})$ added to a milk-based formula. Values are means with their standard errors represented by vertical bars for ten subjects. For details of experimental procedures, see p. 159. 
Thus, information about Se retention and absorption from these products at relevant fortification levels is needed. The daily Se intake in Switzerland is estimated to be 60-70 $\mu \mathrm{g}$ $\mathrm{Se} / \mathrm{d}$ (Pfannhauser, 1994). The administration of $40 \mu \mathrm{g} \mathrm{Se}$ as $\mathrm{SeO}_{3}{ }^{2-}$ or $\mathrm{SeO}_{4}{ }^{2-}$ on two consecutive days increased the total dietary Se intake of the subjects to levels comparable with the upper range of Se intakes in Europe (van Dokkum, 1995). Previous data on Se retention and absorption were based on Se doses ranging up to $200 \mu \mathrm{g} \mathrm{Se}$ (i.e. considerably higher than the daily dietary Se intake in most countries). Our data are therefore more relevant to $\mathrm{Se}$ retention and absorption from Se-fortified foods within the range of habitual dietary Se intakes in Europe. The subjects in the present study were healthy European men with adequate Se status, as judged from blood Se status indicators and $24 \mathrm{~h}$ urinary Se excretion (Robberecht \& Deelstra, 1984; Van Dael \& Deelstra, 1993). Se retention data for $\mathrm{SeO}_{3}{ }^{2-}$ and $\mathrm{SeO}_{4}{ }^{2-}$ found in the present study are in agreement with those of Thomson \& Robinson (1986), who reported Se retention from a $1000 \mu \mathrm{g}$ dietary Se supplement in New Zealand adults using a chemicalbalance technique (mean retention (\%) $\mathrm{SeO}_{3}{ }^{2-} 40, \mathrm{SeO}_{4}{ }^{2-}$ 32). Percentage Se retention was comparable with that found in the present study despite the much higher doses of $\mathrm{Se}$ administered. Our data on Se retention from the test meal labelled with $\mathrm{SeO}_{3}{ }^{2-}$ are within the wide range of reported results (30-75\%) based on stable-isotope techniques (Christensen et al. 1983; Sirichakwal et al. 1985; Martin et al. 1989; Mangels et al. 1990; Finley, 1999). The reasons for the wide range in $\mathrm{SeO}_{3}{ }^{2-}$ retention values are not known, although it can be assumed that factors such as differences in study design, stable-isotope dose, dietary regimen and normal Se intake may play a role.

Previous Se retention studies differed considerably in the number of days (5-21) used in the faecal and urinary collection period (Christensen et al. 1983; Sirichakwal et al. 1985; Martin et al. 1989; Mangels et al. 1990; Finley, 1999). Our data indicate that $\mathrm{Se}$ retention for $\mathrm{SeO}_{3}{ }^{2-}$ and $\mathrm{SeO}_{4}{ }^{2-}$ based on $120 \mathrm{~h}$ collections of faeces and urine was not significantly different from $9 \mathrm{~d}$ balances. However, although our data suggest that complete faecal and urine collection periods shorter than $9 \mathrm{~d}$ may be appropriate for studies of Se retention, it is important to consider carefully the collection time, in relation to factors such as gastrointestinal passage time and dietary habits.

Although retention of the two inorganic forms of Se was found to be similar, a large difference was observed in the percentage absorption of $\mathrm{SeO}_{3}{ }^{2-}$ and $\mathrm{SeO}_{4}{ }^{2-}$; $\mathrm{SeO}_{4}{ }^{2-}$ was almost completely absorbed (91\%) compared with $50 \%$ for $\mathrm{SeO}_{3}{ }^{2-}$. The between-subject variation in $\mathrm{Se}$ absorption was larger for $\mathrm{SeO}_{3}{ }^{2-}(\mathrm{CV} 15 \%)$ than for $\mathrm{SeO}_{4}{ }^{2-}(\mathrm{CV}$ $1.5 \%$ ), and confirmed previously reported data on interindividual variations in $\mathrm{SeO}_{3}{ }^{2-}$ absorption (Martin et al. 1989). A wide range of apparent Se absorption values (35$85 \%$ ) based on stable-isotope techniques have been reported for $\mathrm{SeO}_{3}{ }^{2-}$ (Janghorbani et al. 1982; Christensen et al. 1983; Kasper et al. 1984; Sirichakwal et al. 1985; Martin et al. 1989; Patterson et al. 1989; Mangels et al. 1990; Ducros et al. 1991; Finley, 1999). $\mathrm{SeO}_{3}{ }^{2-}$ has been reported to interact with the lumen content, and therefore it is likely that dietary habits influence Se absorption from
$\mathrm{SeO}_{3}{ }^{2-}$ (Vendeland et al. 1992). Martin et al. (1989) reported that the percentage $\mathrm{SeO}_{3}{ }^{2-}$ absorption in adults fed a Se-restricted diet $(18 \mu \mathrm{g} \mathrm{Se} / \mathrm{d})$ was significantly higher than that of a group fed $118 \mu \mathrm{g} \mathrm{Se} / \mathrm{d}(89 v .58$ respectively). Recently, Finley (1999) also reported significant differences in percentage $\mathrm{SeO}_{3}{ }^{2-}$ absorption between subjects at low $(32.6 \mu \mathrm{g} \mathrm{Se} / \mathrm{d})$ and high (226.5 $\mu \mathrm{g} \mathrm{Se} / \mathrm{d})$ Se intake, but contrary to the data of Martin et al. (1989), higher mean Se absorption (38\% v. $15 \%)$ was reported at the higher Se intake. As in the present study, Thomson \& Robinson (1986) found high Se absorption from $\mathrm{SeO}_{4}{ }^{2-}$ (94 (SD 4) \%) based on the classical balance technique. Finley (1999) reported Se absorption from $\mathrm{SeO}_{4}{ }^{2-}$ in the range of $68-76 \%$ based on a stable isotope technique. Our absorption data and those of Thomson \& Robinson (1986) for both $\mathrm{SeO}_{4}{ }^{2-}$ and $\mathrm{SeO}_{3}{ }^{2-}$ were substantially higher than those reported by Finley (1999). In agreement with the data in human subjects, higher $\mathrm{Se}$ absorption from $\mathrm{SeO}_{4}{ }^{2-}$ v. $\mathrm{SeO}_{3}{ }^{2-}$ was also reported in animals (Wolffram et al. 1985; Vendeland et al. 1992). In those studies $\mathrm{SeO}_{4}{ }^{2-}$ was shown to be rapidly transported across the brush border by a carrier-mediated mechanism, whereas $\mathrm{SeO}_{3}{ }^{2-}$ was absorbed by passive diffusion and showed a strong tendency to bind to the brush border.

Renal excretion is the major pathway for elimination of absorbed Se (Oster \& Prellwitz, 1990). In the present study $\mathrm{Se}$ excretion from $\mathrm{SeO}_{4}{ }^{2-}$ was high; approximately half the $\mathrm{Se}$ absorbed from $\mathrm{SeO}_{4}{ }^{2-}$ was re-excreted in urine compared with only $20 \%$ for $\mathrm{Se}$ absorbed from $\mathrm{SeO}_{3}{ }^{2-}$. The urinary excretion of $\mathrm{Se}$ absorbed from $\mathrm{SeO}_{4}{ }^{2-}$ was also very rapid; $87 \%$ of the total urinary Se excretion was recovered within $24 \mathrm{~h}$ of administration while $90 \%$ of the total $\mathrm{Se}$ excretion of $\mathrm{SeO}_{3}{ }^{2-}$ was completed after $3 \mathrm{~d}$. Thomson \& Robinson (1986) found similar differences for total urinary Se excretion and excretion kinetics between $\mathrm{SeO}_{4}{ }^{2-}$ and $\mathrm{SeO}_{3}{ }^{2-}$ after administration of a single dose of Se $(1 \mathrm{mg})$. Previous stable-isotope data in adults reported urinary excretion for $\mathrm{SeO}_{3}{ }^{2-}$ which was similar to our findings (Martin et al. 1989). The rapid and high Se excretion from $\mathrm{SeO}_{4}{ }^{2-}$ is probably related to its more rapid absorption and metabolism compared with $\mathrm{SeO}_{3}{ }^{2-}$ (Thomson \& Robinson, 1986).

As an alternative to inorganic Se, organic Se could be considered for food fortification. Se retention from organic Se compounds such as selenomethionine and Se-rich yeast has been demonstrated to be high at about 80-90\% (Mangels et al. 1990; Alfthan et al. 1991). Organic Se may not only be incorporated into Se-specific proteins such as GSH-Px and iodothyronine deiodinase but also nonspecifically into blood proteins such as albumin and $\mathrm{Hb}$ due to homology between selenomethionine and methionine. It has been shown that organic and inorganic Se compounds are equally well utilised for incorporation into GSH-Px but that organic Se gives higher plasma and erythrocyte Se levels (Alfthan et al. 1991; Xia et al. 1992; Thomson et al. 1993; Nève, 1995). The metabolic similarity between selenomethionine and methionine has been suggested as the reason for Se toxicity at high $\mathrm{Se}$ intakes (Whanger, 1998).

Se compounds used for fortification of foods for groups 
at risk of low Se intake, such as patients with chronic or acute disease or infants, should ensure adequate absorption and retention of Se. Thus, fortification of nutritional products with $\mathrm{SeO}_{4}{ }^{2-}$ could be considered to be more efficient than $\mathrm{SeO}_{3}{ }^{2-}$. Nevertheless, $\mathrm{SeO}_{4}{ }^{2-}$ may not be the ideal fortificant for individuals with impaired renal function or preterm infants with immature renal function, since $\mathrm{SeO}_{4}{ }^{2-}$ might not be as efficiently excreted as in healthy individuals. For patients with malabsorption syndromes $\mathrm{SeO}_{4}{ }^{2-}$ may be the more appropriate fortification compound, since Se absorption from $\mathrm{SeO}_{3}{ }^{2-}$ has been shown to be markedly reduced in patients with short bowel syndrome (20\%) compared with healthy adults (82\%; Rannem et al. 1996). Finally, concern has been raised about the potential pro-oxidative properties of $\mathrm{SeO}_{3}{ }^{2-}$ and its lower stability compared with $\mathrm{SeO}_{4}{ }^{2-}$ when added to foods (Smith et al. 1995; Tyrala et al. 1996). Although these issues need to be further investigated, they are additional factors potentially in favour of the use of $\mathrm{SeO}_{4}{ }^{2-}$ for $\mathrm{Se}$ fortification of foods.

In conclusion, the results from the present study indicate that $\mathrm{SeO}_{3}{ }^{2-}$ and $\mathrm{SeO}_{4}{ }^{2-}$, when administered within normal dietary intake ranges, were equally well retained in healthy men, although large differences in absorption and urinary excretion were observed. Thus, the nutritional impact of foods fortified with either of these inorganic Se compounds can be assumed to be similar in healthy individuals, at least at the level of Se intake evaluated in the present study.

\section{Acknowledgements}

The authors are grateful for the expert technical assistance of Mrs K. Longet, Mrs S. Metairon, Mrs I. Bartholdi and Mrs J. Clough, and for the fruitful discussions with Dr R. Hurrell and Dr P. Kastenmayer.

\section{References}

Alfthan G, Aro A, Arvilommi H \& Huttunen JK (1991) Selenium metabolism and platelet glutathione peroxidase activity in healthy Finnish men: effects of selenium yeast, selenite, and selenate. American Journal of Clinical Nutrition 53, 120-125.

Beck MA (1996) The role of nutrition in viral disease. Journal of Nutritional Biochemistry 7, 683-690.

Belsten JL \& Wright AJA (1995) European Community - FLAIR common assay for whole-blood glutathione peroxidase (GSHPx). Results of an interlaboratory trial. European Journal of Clinical Nutrition 49, 921-927.

Casey CE \& Hambidge KM (1985) Trace minerals. In Vitamin and Mineral Requirements in Preterm Infants, pp. 153-184 [RC Tsang, editors]. New York: Marcel Dekker.

Chandra RK (1997) Nutrition and the immune system: an introduction. American Journal of Clinical Nutrition 66, 460S-463S.

Christensen MJ, Janghorbani M, Steinke FH, Istfan N \& Young VR (1983) Simultaneous determination of absorption of selenium from poultry meat and selenite in young men: application of a triple stable-isotope method. British Journal of Nutrition 50, 43-50.

Clark LC, Combs GF \& Turnbull BW (1996) Effects of selenium supplementation for cancer prevention in patients with carcinoma of the skin. Journal of the American Medical Association 276, 1957-1963.
Ducros V, Favier A \& Guigues M (1991) Selenium bioavailability as selenite $(74 \mathrm{Se})$ and as a selenium drug $(76 \mathrm{Se})$ by stable isotope methodology. Journal of Trace Elements and Electrolytes in Health and Disease 5, 145-154.

Finley JW (1999) The retention and distribution by healthy young men of stable isotopes of selenium consumed as selenite, selenate or hydroponically-grown broccoli are dependent on the isotopic form. Journal of Nutrition 129, 865-871.

Hambidge KM (1985) Trace elements in human nutrition. In Nutrition in Pediatrics. Basic Science and Clinical Applications, pp. 7-45 [WA Walker and JB Watkins, editors]. Boston, MA: Little Brown Co.

Hills M \& Armitage P (1979) The two-period cross-over clinical trial. British Journal of Clinical Pharmacology 8, 7-20.

Janghorbani M, Christensen MJ, Nahapetian A \& Young VR (1982) Selenium metabolism in healthy adults: quantitative aspects using the stable isotope ${ }^{74} \mathrm{SeO}_{3}{ }^{2-}$. American Journal of Clinical Nutrition 35, 647-654.

Kasper LJ, Young VR \& Janghorbani M (1984) Short-term dietary selenium restriction in young adults: quantitative studies with the stable isotope ${ }^{74} \mathrm{SeO}_{3}{ }^{2-}$. British Journal of Nutrition 52, 443-455.

Kelly DA, Coe AW, Shenkin A, Lake BD \& Walker-Smith JA (1988) Symptomatic selenium deficiency in a child on home parenteral nutrition. Journal of Gastroenterology and Nutrition 7, 783-786.

Levander OA (1984) The importance of selenium in total parenteral nutrition. Bulletin of the New York Academy of Medicine 60, 144-155.

Litov R \& Combs G (1991) Selenium in pediatric nutrition. Pediatrics 87, 339-351.

Lockitch G (1989) Selenium: clinical significance and analytical concepts. CRC Critical Reviews in Clinical Laboratory Sciences 27, 483-539.

Makarem A (1974) Trace elements in human nutrition. In Principles and Techniques, 2nd ed., pp. 1125-1147 [RJ Henry, DC Cannon and JW Winkelman, editors]. Hagerstown, MD: Harper \& Row.

Mangels AR, Moser-Veillon PB, Patterson KY \& Veillon C (1990) Selenium utilization during human lactation by use of stable-isotope tracers. American Journal of Clinical Nutrition 52, 621-627.

Martin RF, Janghorbani M \& Young VR (1989) Experimental selenium restriction in healthy adult humans: changes in selenium metabolism studied with stable-isotope methodology. American Journal of Clinical Nutrition 49, 854-861.

National Research Council (1989) Recommended Dietary Allowances, 10th ed. Washington, DC: National Academy Press.

Nève J (1995) Human selenium supplementation as assessed by changes in blood selenium concentration and glutathione peroxidase activity. Journal of Trace Elements in Medicine and Biology 9, 65-76.

Oster A \& Prellwitz W (1990) The renal excretion of selenium. Biological Trace Element Research 24, 119-146.

Patterson BH, Levander OA, Helzlsouer K, McAdam PA, Lewis SA, Taylor PR, Veillon C \& Zech LA (1989) Human selenite metabolism: a kinetic model. American Journal of Physiology 257, R556-R567.

Pfannhauser W (1994) Neue Forschungsergebnisse über Selen (New research data on selenium). Ernärhrung 18, 75-76.

Rannem T, Hylander E, Ladefoged K, Staun M, Tjellesen L \& Jarnum S (1996) The metabolism of $\left[{ }^{75} \mathrm{Se}\right]$ selenite in patients with short bowel syndrome. Journal of Parenteral and Enteral Nutrition 20, 412-416.

Robberecht HJ \& Deelstra HA (1984) Selenium in human urine. Determination, speciation and concentration levels. Talanta 7 , 497-508. 
Sandström B, Fairweather-Tait S, Hurrell R \& van Dokkum W (1993) Methods for studying mineral and trace element absorption in humans using stable isotopes. Nutrition Research Reviews 6, 71-95.

Sirichakwal PP, Young VR \& Janghorbani M (1985) Absorption and retention of selenium from intrinsically labeled egg and selenite as determined by stable isotope studies in humans. American Journal of Clinical Nutrition 41, 264-269.

Smith AM, Chen LW \& Thomas MR (1995) Selenate fortification improves selenium status of term infants fed soy formula. American Journal of Clinical Nutrition 61, 44-47.

Thomson CD \& Robinson MF (1986) Urinary and fecal excretions and absorption of a large supplement of selenium: superiority of selenate over selenite. American Journal of Clinical Nutrition 44, 659-663.

Thomson CD, Robinson MF, Butler JA \& Whanger PD (1993) Long-term supplementation with selenate and selenomethionine: selenium and glutathione peroxidase (EC 1.11.1.9) in blood components of New Zealand women. British Journal of Nutrition 69, 577-588.

Turnlund JR, Keyes WR \& Peiffer GL (1993) Isotope ratios of molybdenum determined by thermal ionisation mass spectrometry for stable isotope studies of molybdenum metabolism in humans. Analytical Chemistry 65, 1717-1722.

Tyrala EE, Borschel MW \& Jacobs JR (1996) Selenate fortification of infant formulas improves the selenium status of preterm infants. American Journal of Clinical Nutrition 64 , $860-865$.

Van Dael P, Barclay D, Longet K, Metairon S \& Fay LB (1998) Determination of selenium stable isotopes by gas chromatography-mass spectrometry with negative chemical ionisation. Journal of Chromatography 715B, 314-317.

Van Dael P \& Deelstra H (1993) Selenium. International Journal of Vitamin and Nutrition Research 63, 312-316.

Van Dael P, Van Cauwenbergh R, Deelstra H \& Calomme M (1995) Determination of selenium in human serum by longitudinal Zeeman correction and flow injection hydride generation atomic absorption spectrometry. Atomic Spectroscopy 16, 251-257.

van Dokkum W (1995) The intake of selected minerals and trace elements in European countries. Nutrition Research Reviews 8 , 271-302.

Vendeland SC, Butler JA \& Whanger PD (1992) Intestinal absorption of selenite, selenate, and selenomethionine in the rat. Journal of Nutritional Biochemistry 3, 359-365.

Vinton NE, Dahlstrom KA, Strobel CT \& Ament ME (1987) Macrocytosis and pseudo-albinism: manifestations of selenium deficiency. Journal of Pediatrics 111, 711-777.

Whanger PD (1998) Metabolism of selenium in humans. Journal of Trace Elements in Experimental Medicine 11, 227-240.

Wolffram S, Ardüser F \& Scharrer E (1985) In vivo intestinal absorption of selenate and selenite by rats. Journal of Nutrition 115, 454-459.

Xia Y, Zhao X, Zhu L \& Whanger PD (1992) Metabolism of selenate and selenomethionine by a selenium-deficient population of men in China. Journal of Nutritional Biochemistry 3, 202-210.

Zachara BA (1993) Mammalian selenoproteins. Journal of Trace Elements in Health and Disease 6, 137-151. 